Indian Society of Neuroanaesthesiology and Critical Care (ISNACC 2017) conference report

\section{Ankur Luthra}

The $18^{\text {th }}$ Annual Conference of Indian Society of Neuroanaesthesiology and Critical Care (ISNACC 2017) was organised at the Bhargava Auditorium, Postgraduate Institute of Medical Education and Research (PGIMER), Chandigarh, India. It was an amalgamated effort by Prof. Nidhi Panda (organising secretary) and Dr. Hemant Bhagat (co-organising secretary) who conducted this conference in collaboration with the Department of Anaesthesia and Intensive Care, PGIMER, Chandigarh.

With an ever-changing intricacy and ramifications in neuroanaesthesia and neurocritical care, and its rapid progression, the theme of this year's conference was 'Challenges in Neuroanaesthesia with Focus on the Future'. Prominent international faculty and notable national faculty pondered their knowledge towards the progress in the field of neuroanaesthesia and neurocritical care during the conference which was attended by more than 500 delegates from around the globe.

The 3 days of this academic extravaganza started on $24^{\text {th }}$ February 2017. On day 1, training course and workshop was conducted on multimodal neuromonitoring, ultrasound and echocardiography in neuroanaesthesia and difficult airway management which also included hands-on training for which around 130 delegates participated and made these workshops successful.

Department of Anaesthesia and Intensive Care, Division of Neuroanaesthesia, Postgraduate Institute of Medical Education and Research, Chandigarh, India

Address for correspondence:

Dr. Ankur Luthra, H. No. 979, Aashirwad Enclave,

Sector 49-A, Chandigarh - 160 012, India.

E-mail: zazzydude979@gmail.com
Simultaneously, the scientific sessions began with 'Emergency in neuroanaesthesia,' under the following topics: 'Pattern and categorisation of neurosurgical emergencies', 'Trigeminocardiac Reflex: Mechanism and clinical implications', 'management of emergency situations in elective neurosurgery' and 'Emergency in Neurosurgical Suite' delivered by Dr. D. Kulkarni, Dr. Gyaninder Pal Singh, Dr. Ratan Chelani and Dr. Saurabh Anand, respectively. Later session included 'Pros and cons on use of desflurane in neuroanaesthesia' by Dr. Smita Sharma and Dr. Shashi Shrivastava, and panel discussion on 'Does specialised training in neuroanaesthesia make a difference to patient outcome?' which was moderated by Dr. Joseph Monteiro. After the tea break, a session on 'neurocritical care' with the lectures on 'Goals of management of critically ill neurosurgical patients', 'Pain management in neurocritical care' and 'Is paediatric neurocritical care different from adults?' was presented by Dr. Jaya Wanchoo, Dr. Mritunjay Verma and Dr. Ponniah, respectively. The session on 'Fluid therapy' included 'Colloids in neurosurgical patients', 'Does balanced intravenous fluids impact outcome in neurosurgical patients' and 'Goal-directed fluid management in patients with traumatic brain injury (TBI)' which were delivered by Dr. Bibukalyani Das, Dr. Venkatesh HK and Dr. D. P. Samaddar, respectively.

Post-lunch sessions included Hariwir Singh Oration by Dr. Ravi Mahajan on 'Patients Safety: Have we been barking up the wrong tree?' Furthermore, this conference highlighted various video presentations on 'Scalp block' by Dr. Irene Osborn, 'Anaesthesia for DBS' by Dr. Rajshree Deopujari, 'Cervical spine movement during intubation' by Dr. Amlan Swain and 'ECG-guided central venous cannulation' by Dr. Banashree Mandal. To close the day, the final session was concluded by Dr. Kanchan K. Mukherjee who associated Mahabharata with neurosciences in his lecture on 'Hiranyagarbha to Hypothalamus: A journey from mythology to neuroscience' which piqued interest of many delegates. It was followed by a general body meeting among members of ISNACC.

The scientific programme on day 2 commenced with the session on 'TBI' which included 'Cerebral autoregulation in TBI: Where do we stand?', 'Biomarkers and prognostication in TBI' and 'What can impact outcome in TBI: Evidence to clinical practice' which were delivered by eminent professors Dr. Adrian Gelb, Dr. G. S. Umamaheshwara Rao and Dr. Parmod Bithal, respectively. G. R. Gode Oration was delivered 
by Dr. Gundappa Parameswara on 'Extra-cranial complications in head injury - What is new'. Later sessions included 'Paediatric neuroanaesthesia' focussing on 'Challenges in paediatric neurosurgery', 'Fluid management in infants and children during intracranial surgery', 'Haemoglobin levels for transfusion trigger in paediatric neurosurgical patients' and 'Anaesthetic concerns and management in children with craniopharyngioma' which were delivered by Dr. Pragati Ganjoo, Dr. Hemangi Karnik, Dr. V. J. Ramesh and Dr. Srilata, respectively. Another interesting Pro-Con session was debated upon by Dr. Swagata Tripathy and Dr. Monica Tandon on 'Invasive versus non-invasive ICP monitoring'. The session on stroke included some of the recent scenarios on 'Recognition and management of stroke', 'Metabolic monitoring tools in patients with stroke' and 'Current trends in mechanical thrombectomy in patients with acute ischaemic stroke' which were delivered by Dr. Aastha Takkar Kapila, Dr. Prabu Anandaraj and Dr. Vivek Gupta, respectively. Post-lunch sessions on 'Challenges in neuroanaesthesia' included 'Awareness in neuroanaesthesia', 'The use of electroencephalography in neuroanaesthesia', 'Management of intraoperative brain bulge despite standard care' and 'Management of spinal cord injury' which were aptly discussed by Dr. Rahul Bajekar, Dr. Lorenzo Dimple, Dr. Amit Jain and Dr. Neeraj Kumar, respectively. The video sessions of the day included 'ICP monitoring' by Dr. Radhakrishnan, 'Intraoperative electrophysiological monitoring' by Dr. Ashok Jaryal, 'Intraoperative electrocorticography' during epilepsy surgery by Dr. Pirjo Manninen and 'Cerebral Microdialysis' by Dr. Girija Prasad Rath. The final session of the day included interesting case scenarios on 'Pregnancy and subarachnoid haemorrhage (SAH)' and 'Odontoid fracture in patients with aortic stenosis' which were presented by Dr. Kiran Jangra and Dr. Ankur Luthra, respectively, in the session of problem-based learning and discussion. The inaugural function followed later which was presided over by his excellency Acharya Dev Vrat, governor of Himachal Pradesh, who was invited as the chief guest for the occasion.

The final day of the conference was exclusively meant for the International Symposium on Aneurysmal $\mathrm{SAH}$ which began with introductory keynote by Dr. Hemant Bhagat which was followed by 'Epidemiology and pathophysiology of SAH' which was delivered by Dr. Sucharita Chakravarti and 'Biomarkers of SAH' were discussed by Dr. Akhilesh Pandey. The SNACC panel then emphasised upon 'Anaesthetic management', 'Neuroprotection' and 'Intensive Care Unit management of $\mathrm{SAH}^{\prime}$ which were delivered by the eminent international faculty members Dr. Deepak Sharma, Dr. David Warner and Dr. Mike Souter from the USA, respectively. In the later half, Malathi Memorial Oration was delivered by Dr. M. T. V. Chan who spoke on the current role of statins in aneurysmal SAH. After the oration, six papers were presented by residents from various institutes across India which were judged by Dr. Hilary Grocott and Dr. Adrian Gelb for the eminent Prof. Y. S. Verma award. The session on systemic manifestations of SAH included 'Cardiovascular manifestations' and 'Fluid and electrolyte management with aneurysmal SAH' which were delivered by Dr. K. S. Manikandan and Dr. Peter Farling, respectively, which was followed by a panel discussion on 'Clipping versus coiling of intracerebral aneurysm: Are we still at cross roads?' moderated by Dr. Ashish Pathak and the panellists were Dr. Adrian Gelb, Dr. N. Khandelwal, Dr. M. K. Tiwari and Dr. C. E. Deopujari. The session on post-operative course included 'Management of cerebral vasospasm' and 'Outcome and rehabilitation of patients following aneurysmal SAH' which were presented by Dr. H. H. Dash and Dr. Dhaval Shukla, respectively. To conclude the scientific program, Dr. Manjul Tripathy delivered an interesting talk on 'Cricket and neurosciences'.

The conference was not only a scientific extravaganza but also an audio-visual treat to all the delegates with the residents of the Department of Anaesthesia performing on Bollywood dance numbers which was cherished by all, and to wind up the cultural activities on day 1, the Morphine band performed with heart and soul and rejuvenated everyone. On day 2, the inaugural function was followed by professional dances 'Kumaon' (dance form of Uttarakhand), Nati (dance form of Himachal Pradesh) and Gatka (martial art form of Punjab) which was followed by well-arranged and well-decorated dazzling banquet dinner.

There were 64 poster presentations which included both case reports and research papers from all over the world on the first 2 days of the conference. This was followed by valedictory function and prize distribution to all the winners including poster presentation and quiz. Prof. Y. S. Verma award for the best research paper was awarded to Dr. Shalvi Mahajan from PGIMER, Chandigarh.

The organising secretary and co-organising secretary thanked the organising team for making the conference a successful venture and a mega event which was very much appreciated by all the delegates and participating national and international faculty. 
Financial support and sponsorship Nil.

\section{Conflicts of interest}

There are no conflicts of interest.
This is an open access article distributed under the terms of the Creative Commons Attribution-NonCommercial-ShareAlike 3.0 License, which allows others to remix, tweak, and build upon the work non-commercially, as long as the author is credited and the new creations are licensed under the identical terms.

\begin{tabular}{|l|l|}
\hline \multicolumn{2}{|c|}{ Access this article online } \\
\hline Quick Response Code: & Website: \\
\hline & www.jnaccjournal.org \\
\cline { 2 - 2 } & \\
\hline
\end{tabular}

How to cite this article: Luthra A. Indian Society of Neuroanaesthesiology and Critical Care (ISNACC 2017) conference report. J Neuroanaesthesiol Crit Care 2017;4:129-31. 